\title{
Contemporary environmentalism as a current of spiritual post-secular practice
}

\section{Introduction}

Today many people, both within and outside of traditional religious structures experience a profound sense of something spiritual and holy existing in the natural world. The outdoors and the wilderness feel sacred for many, whether they define this sacredness as a connection to a transcendent, divine, creative force, or to the immanent reality of ecological interdependence. Many might also describe such an experience as spiritual rather than religious (Bauman et al. 2011: 2).

Susan Baker and Robin Morrison (2011) describe spirituality as an inherent component of being human and it is also subjective, intangible, and multidimensional. Spirituality involves an individual's search for meaning in life; for wholeness, peace, individuality, and harmony. Spirituality is culturally conditioned and enriched outside the narrow borders of any one particular religion. But spirituality can also be described as a way of living, as something which can be expressed, for example through personal activities such as meditation. It can also ground social action. A spiritual journey moves through contemplation and reflection to action. When we discuss spirituality or engage in spiritual dialogue, this can provide means for building spiritual community through engagement and action (Baker \& Morrison 2011: 63-5).

According to Giselle Vincett and Linda Woodhead (2009) contemporary spirituality often bears the stamp of an eco-discourse. It is characteristic of post-spiritual practices that there is a blurring of the boundaries between the sacred and profane and in this sphere, influenced by the eco-consciousness, nature and the body can be sacralised (Vincett \& Woodhead 2009: 333). In this article I will look into environmentalism as a current in spirituality. First I discuss spirituality based on two recent articles by Ulrike Popp-Baier (2010) and Frans Jespers (2011), published in The Journal for Religion in Europe. Second follows a section on aspects of contemporary environmentalism, dealing with new social movements, new identity and the main directions of environmentalism. After that I present Susan Baker and Robin Morrison's 
(2011) distinction between environmentally motivated spirituality and spiritually motivated environmentalism, based on their article 'Environmental Spirituality: Grounding our Response to Climate Change'. At the end there is a short discussion of post-secular issues concerning environmentalism.

\section{Characteristics of spirituality}

Spirituality is an extremely nuanced term and therefore difficult to define, since it is ever changing. Ulrike Popp-Baier argues that the word spirituality is preferred over the word religion in many areas such as the media, health and business (Popp-Baier 2010: 61). According to Frans Jespers (2011: 328), this has to do with the fact that spirituality is such a fluid and contested, but inescapable concept, embracing different meanings in various contexts. Popp-Baier writes that in empirical studies about the religious landscape in the 1990s, the distinction between religion and spirituality has often been described as institutional objective versus personal objective, static versus dynamic, outward versus inward, doctrinal versus experiential, conventional versus unconventional and cognitive versus emotional (Popp-Baier 2010: 45).

In her overview of ways in which spirituality has been defined, PoppBaier presents Michelle Dillon and Paul Wink's understanding of spirituality as spiritual seeking in contrast to religious dwelling and how Paul Heelas and Linda Woodhead, who have been inspired by Charles Taylor, describe a change in modern culture. This change has taken place from the 'life-as' view of life as parent, child, student, self-made man and so on, to 'subjective-life', which embraces the view of life as being lived in connection with the experience of one's self-in-relation. The distinction between religion and spirituality can be redefined through the concepts of life-as religion and subjective-life spirituality (Popp-Baier 2010: 46).

Popp-Baier emphasises another trend within research into spirituality. Other researchers, such as Brian Zinnbauer and Kenneth Pergament, have tried to avoid the polarization of setting one thing versus another and have focused on the relationship to, or search for the sacred concerning both spirituality and religiousness. They argue that sacredness is distinctive of religiousness and spirituality, the sacred being the substantive core of both. Ralph Hood has identified spirituality from the view of inwardness, through core elements such as inner psychological processes, inner experiences, or inner capacity. Hood has also described modern spirituality as a form of modern classical mysticism (Popp-Baier 2010: 48-9), a view which is supported 
by Antoon Geels, who asserts that the defining characteristics of grassroots spirituality can be recognized in classical mysticism (Geels 2009: 20). Jespers criticises this approach which defines religion and spirituality as the quest for the sacred, but admits that these scholars usually have a more critical position than simply this (Jespers 2011: 338).

One reason for the multiple methods of application and the way spirituality is used is that the concept of spirituality is of recent derivation in the study of religion. In his overview of the occurrence of the word, Jespers concludes that the concept is rarely found in handbooks and run-throughs before 2000. There is a difference between the Anglo-Saxon and European tradition as well. When the American, early understanding of spirituality emerged in the nineteenth century, with a focus on the alternative trends in personal and deeply experienced spirituality, the European understanding of the term spirituality had long been influenced by engaged (Christian) piety. Gradually a new stream of spirituality emerged in Europe as an alternative to mainstream religion, to include a spectrum ranging from individual practices to tightly organised and highly committed paganism. Common for these sectors is that they all have a positive view of self-development, the quest for wisdom and social and ecological commitment (Jespers 2011: 329-32).

\section{New spirituality}

According to Jespers, new spirituality is partly an effect of three processes in Western modernisation; namely those of equality, individualisation and colonialism (Jespers 2011: 332). Concerning the religious individualism of contemporary religiosity, the view that an individual does not need an intermediary and that the person themself has the responsibility for his/her own spiritual destiny could be cited as characteristic of this phenomenon. Dominika Motak (2009) refers to Heelas when she describes new spirituality in terms of religion as deregulated and moulded to the individual. Furthermore, when new spirituality is combined with freedom of choice, the result is an intermingled and interfused form of religious life, which cannot be described with the traditional vocabulary and symbols more commonly used in religion (Motak 2009: 152).

Furthermore, the new spirituality is often influenced by similar late modern existential movements such as feminism, occultism, romanticism and environmentalism, and these new spiritual movements became popular after 1990. Jespers lists additional problems to the use of the term spirituality, 
which mainly stem from an unclear use of the term and a lack of clear concepts. Jespers explains these difficulties in terms of the diversity of ways in which the term is used and that some spiritual practices are called religious. What contributes to the confusion is that if spiritual practices are called religious, then non-religious practices should logically be called secular. The subtle use of the terms religious, secular, spiritual and so on, is more than vague. Another difficulty lies in the fact that the adherents or supporters of spirituality do not represent a unified group, but a diverse range of ideas. As opposed to mainstream religion where ethical rules, doctrines and texts are central, practices such as meditation, healing, worship and therapy seem to be primary in new spiritual movements (Jespers 2011: 330-5). Most of these practices include the body as a means of connecting to the sacred. Through embodiment the person and the environment are interwoven into a holistic unity.

Popp-Baier pays attention to the fact that the terms spirituality and religion have often been used in different ways and therefore a clarification of the concept of spirituality would require a clarification of terms such as religion and religiousness as well. She adds that it is important to discover what people in fact mean when they answer surveys identifying or describing themselves as spiritual, religious, both or neither (Popp-Baier 2010: 42-4, 45).

Regardless of all the attempts at defining spirituality, Popp-Baier highlights three problematic areas: 1) such definitions conflict with the historical use of the term; 2) they do not agree with the self-perceptions of those people who explicitly see themselves as neither religious nor spiritual; and 3), the definitions are too inclusive for people to search for existential meaning at a conceptual level in order to recognise or distinguish between various ways. To identify and reconstruct the contemporary meanings of terms such as spirituality in the way they are used by different people in various contexts are included, according to Popp-Baier, in the task of the social scientists (PoppBaier 2010: 51-2). Scholars such as Richard Carrette and Richard King have explicitly stated that it is impossible to define either religion or spirituality (Jespers 2011: 338).

\section{Self-controlled religiosity}

If spirituality is considered to be a relatively new modern religious phenomenon, this view, combined with a disunity of opinion as to whether spirituality can be called religious activity/ideology or not, has led to a sort of contradic- 
tion. Analyses of these societal patterns, explicitly by scholars who consider spirituality as a modern phenomenon, have led to cultural macro-theories, or grand explanations (Jespers 2011: 337-9). Popp-Baier has criticised the theory of grand explanations by pointing out the weaknesses in the form of a lack of empirical understanding. She has developed and introduced the concept of self-controlled religiosity, which is a combination of critique, consumption and accommodation and might even include commitment concerning religion (Popp-Baier 2010: 59).

Popp-Baier has recognized elements that people consider to be religious, or examples of how people currently use religion. They are, among other things, ways of coping with problems, or of constructing individual philosophies and substance for self-enhancement and to improve subjective wellbeing. The fact that people are better informed about other religious belief systems than in previous times does not mean that people have the capacity or willingness to embrace them fully, but more often they select parts from these different belief systems to fit their personal needs and interests (PoppBaier 2010: 59-60).

Different elements are often combined into syntheses of individual religiosity, which may change and evolve during life. The same people might regard themselves as rational agents, but at the same time accept that life also has irrational and uncontrollable elements and therefore includes a transcendental aspect. Popp-Baier stresses that it is in relation to this transcendental aspect that processes of reflection, evaluation, comparison and decision are crucial (Popp-Baier 2010: 60). According to Jespers, Popp-Baier misses the issues of critical observation and methodology (Jespers 2011: 350).

As we have seen above, recent decades have brought changes both in the social form of religion/spirituality and in individual religiosity/spirituality. According to Motak, both of the social and individual forms have become more subjective and spiritual. Motak asserts that the return of the sacred is present, but is taking a different form. In the new world-view there is a presupposition of the presence of the divine in humans and in the world and an essential oneness of the microcosm and macrocosm. The central notion is the idea of the immanence and the sacredness of life, nature and the universe (Motak 2009: 149). This type of spirituality takes various forms of expression and next I will explore some aspects of one of its trends; namely, contemporary environmentalism. 


\section{Aspects of contemporary environmentalism}

Environmental movements, together with others such as feminism and the gay movement, are often considered to belong to the new social movements. Peter Beyer (1994: 98) indicates the long silence concerning religion as an important factor in the study of these new social movements, although religious actors and organisations are often directly involved with each other.

These movements are producing new forms of belonging, with participants searching for another kind of relationship with themselves. This new social movement paradigm, presented by Alexander Koensler and Cristina Papa (2011), who have been influenced among others by Alberto Melucci and Alain Touraine, raises the issue that in contrast to the 'old' movements which mobilised primarily in order to access resources; these 'new' movements are distinctive in their creation of new identities and concepts of belonging (Koensler \& Papa 2011: 13). The new social movements represent a liberal religious option as well. Conservative religious movements have traditionally stressed religio-political emphasis and from the benefits of industrial society there has been, according to Beyer, a shift of emphasis onto more cultural concerns with the quality of life and the idea of a good society. More liberally oriented adherents seem to favour the aims and methods of the latter in the form of new social movements (Beyer 1997: 98).

Ingrid Hoofd (2009) uses the term 'speed elitism' to describe certain sites of power in contemporary societies. Concurrently with the social stratification of societies, the access to new technologies and geographical mobility increases. Simultaneously speed, politics and power are increasingly linked. Hoofd argues that new social movements, in order to mobilise, often rely on 'the fantasy of an authentic "voice" from an oppressed group', which according to Hoofd takes the form of 'the people' or 'the multitude' (Hoofd 2009: 209). The general acceleration of life through communication technologies enables and encourages this faith in the possibility of advancing social justice through connectivity, international mobility and the overcoming of boundaries. Yet, rather than representing a move away from neo-liberal logic, this acceleration is itself an expression of that logic. The highly technologically and globally connected spaces, in which many of the activists of the emergent 'speed elite' operate, are precisely the products of the advancement of neo-liberal practices and values (Koensler \& Papa 2011: 14-15).

Contemporary environmentalism is an example of how new social movements can create a new form of identity and belonging which is not connected to institutionalized religiosity, but offers a way of creating one's own outlook 
on life. Concern about the state of the environment we live in can motivate and give significance to spiritual activity, as a response to the blurring of the boundaries between the sacred and profane. Whether the environment is seen as purely functional, or sacred in itself, contemporary environmentalism often includes a spiritual dimension.

There are various internal groupings within contemporary environmentalism, but the three best known are eco-spirituality, eco-justice and ecotraditionalism. The differences between them are more a matter of emphasis than of fundamentally oppositing views, but the adherents of the different views do clash occasionally. Adherents of eco-justice have criticised adherents of eco-spirituality as being irresponsible 'tree-huggers' while children starve and for eco-spiritualists the other two groups are not spiritual enough. The main dividing line between the environmentalists is in the end, though, between liberal and conservative opinions. Eco-traditionalists seek to revitalise the tradition my means of reforming traditional religious texts in the light of ecological issues, while eco-spiritualists often advocate a new religion, even though they often use already existing religious symbolism. Unlike eco-traditionalism and eco-spirituality, which focus more on religious function, ecojustice focuses more often on pragmatic compromises. The different views mirror rather various relations between religious function and performance, which has consequences of public influence (Beyer 1997: 219-21).

Baker and Morrison (2011) have created a distinction between environmentally motivated spirituality and spiritually motivated environmentalism, which I will follow in this article. The former instance, environmentally motivated spirituality, refers to people whose experiences in nature transcend the scientific, material environment. The latter, spiritually motivated environmentalism, is where spirituality provides guidance and motivation in work on environmental causes.

\section{Environmentally motivated spirituality}

In environmentally motivated spirituality nature may be thought of in different ways, such as in terms of wilderness as opposed to countryside or garden, or in terms of urban environments and the global environment. The notion of wilderness is often linked with either the idea that there is a pure, real nature 'out there', or with the notion of a return to an original, pure nature, even if this return is only for a short period. The countryside or garden represents a more domesticated view of nature, often associated with a sense of cultural identity, 
such as the English countryside, or with past times or even with political projects, such as the neo-rural movement of the late twentieth century. The focus on the idea of the urban environment stems from a growing awareness that, for the vast majority of people now and even more so in the future, their encounters with nature will primarily be within the urban setting. Attempts to capture or recreate the 'natural' environment have been made by developing city farms and inner city wildflower parks (Baker \& Morrison 2011: 65-6).

At present, we tend to understand nature as that which is apart from an urban setting, something that we have to bring into the city for its inhabitants to experience and enjoy. The view of the global environment owes much to earlier works on the Gaia hypothesis by James Lovelock. Climate change in particular has focused attention on nature as being a set of ecosystems, as seen from a planetary perspective. Here nature is seen as being under threat and this has given rise to a politics of anxiety: fear for our future, distrust in the political system, including international environmental governance regimes such as the United Nations (UN), to actually solve our collective problem and ensure our collective future (Baker \& Morrison 2011: 65-6).

This anxiety is also reflected in our feeling of security. Security is not just something states provide for their citizens. Individuals can become insecure if their fields are subject to erosion, if their forests are being used faster than they can regenerate, their climate is becoming drier because of global warming, or if their animal's manure is all needed for fuel and is no longer available to fertilize the rice-fields. As the resource base disappears and people are no longer able to support themselves and their families, one consequence that we already have started to see are environmental refugees. When adding all these tiny individual losses of security together there is a major national or regional, or even a global security problem. Security is something that can be created and destroyed at every level-from the private household all the way up through firms, to nation states and regional groupings of states to international regimes (Thompson 1997: 1-2).

Moreover these different views of nature also involve different sets of views about human beings and their relationship to nature, that is to say, the anthropocentric and the ecocentric views. Implicit in Western thought there is an idea that human beings are outside, or even above nature. From this point of view nature is given only a utilitarian value, that is, nature is valued only in terms of the uses that it can have for human beings. By this reasoning the term nature is often replaced with the term 'natural resource base'. Human progress has come to be understood in terms of increased domination over nature and the use of resources solely for the benefit of humankind. This 
view was not only confined to business or politics, but was also the dominant view in Western environmental movements in the 1970s and 1980s, where the major concern of the movement at that time was with pollution and resource depletion. Pollution was a concern specifically because of its impact on human health and resource depletion was of concern because of its potential to undermine further economic development (Baker \& Morrison 2011: 66).

The anthropocentric approach can be contrasted with an ecocentric view of nature and of the position of human beings in the natural world. This view emphasises the value that nature has over and above its usefulness to humans. In the ecocentric view, human beings are seen as being an inherent part of nature and there is a particular set of beliefs about how environmental resources are used. In contrast with the anthropocentric position, the ecocentric position allows nature to set the parameters of economic behaviour (Baker \& Morrison 2011: 67).

The social, economic, environmental, political and/or ethical notions of de-growth have assumed an increasingly high profile within political discourse and social action over the last decade. Drawing on prominent environmental concerns, such as limits to growth, climate change and peak oil, and related social anxieties over the increasing globalisation of the economy and the normalisation of excessive consumption, de-growth raises important questions for those concerned with the composition of environmental values in the twenty-first century. While profits have been the principle traditional indicators of economic growth, ecological economists such as Herman Daly, Robert Costanza, Richard Norgaard and Hazel Henderson have developed a new field of study and practice. They have formed an international Society for Ecological Economics and are challenging models of economic growth and development along with conventional methods of costs accounting that disregard the environment (Grim \& Tucker 2011: 87).

The anthropocentric and the ecocentric positions each have important ethical implications, in particular in relation to the design and implementation of policies. The ecocentric approach focuses on the community level and espouses small-scale, locally based technology. Its objective is to maintain social and communal wellbeing and the emphasis is on social purpose and values. In contrast, the anthropocentric approach can be distinguished by its optimism over the successful manipulation of nature and its resources in the interests and for the benefit of humankind. My aim is not to create a stance of opposition, but rather to state that depending on which position we choose to follow and implement, there are far-reaching ethical consequences. Many environmentalists who search for an environmentally motivated spirituality 
are, perhaps not surprisingly, closer to the ecocentric position than to the anthropocentric position (Baker \& Morrison 2011: 67).

\section{Spiritually motivated environmentalism}

In order for spiritually motivated environmentalism to be able to provide guidance and motivation to work on environmental causes, a cultural awareness of the interrelationship between the natural environment, humans and the continuity of life need to be embraced.

Tony Watling (2009) argues that what is seen to be needed is a fundamental reorientation of humanity in nature, a view which includes holistic and spiritual knowledge. Beyer recognizes global environmental issues as being part of the question of holism, since all actions are interconnected. Furthermore, since global environmental problems are a result of uneven power relations in the system of globalization, the solution to the problems is to be found in the global society and how to conceive of that society. This is, according to Beyer, an existential question that affects spiritually and religiously motivated people, since 'the meaning of the whole is immanence profiled by positing transcendence' (Beyer 1997: 209).

Watling refers to Max Oelschlaeger, who in 1994 wrote that environmental ethicists should consider that any single mainstream religious denomination alone influences the normative choices of more people than all eco-philosophies put together. Even though times have changed in Western culture, the impact of religious influence worldwide should not be underestimated. In line with the thinking of religious reorientation, religious traditions are being encouraged to engage with environmental issues (Watling 2009: 7). Environmental issues exist in a certain tension of social justice and hence religious or spiritually motivated environmentalism is one of the strongest actors dealing with social justice (Beyer 1997: 112).

Besides the ecocentric aspect, which all religious traditions have, Watling emphasises the importance of acknowledging the anthropocentric aspect. Even the environmentalists need to be aware that the concept of nature is culturally determined and that any static position of what nature is, or how it should be addressed, is limited and can be challenged. Therefore even the dichotomies of modern or ecological notions of nature can be seen as forms of social control through creating a hegemonic environmental norm (Watling 2009: 21-2). 
Though much work has been done within academic institutions, the field of religion and ecology also depends on work done within religious institutions. Scientists have for years asked religious communities to play a more active role in environmental issues because they have observed that moral authority has played an important role in many transformations of values and behaviour (Grim \& Tucker 2011: 90-1). Secular environmentalists have made the same observation and connection. Even publications by secular environmentalists and environmental organisations often contain at the least indirect religious interpretations and some direct recognition that some traditional religions address environmental issues at the core of their doctrines (Beyer 1997: 209).

After the Second World War public policy makers and academics in Western Europe and North America were heavily influenced by distinct secularisation theory. The role of faith was systemically ignored, since, for example, poverty was perceived of as a matter of material deprivation and its elimination a technical undertaking. This antipathy was frequently reciprocated. Faith leaders often considered themselves to be the defenders of traditional moral values, but emphasised the spiritual and moral dimensions of social problems. Since 1997, however, development organisations have become more conscious of the salience of religion in international politics and its importance for development policy and practice (Clarke 2009: 385-6).

While religions have their problematic dimensions, including intolerance, dogmatism, and fundamentalism, they have also served as sources of wisdom and moral inspiration and as containers of transformative ritual practices (Grim \& Tucker 2011: 90-1). One example of this recognition of religions addressing environmental issues is the 25th Anniversary meeting of the World Wildlife Federation (WWF), which took place in Assisi, Italy, in 1986. WWF invited leaders of five major world religions to start and develop a network which has since then grown and published its own periodicals (Beyer 1997: 209). Even in deeply structured international business organisations the recognition of the connection between faith and action can be observed, as when, for example, the former President of the World Bank, James Wolfensohn, in 1997 launched a small 'Directorate on Faith' within the Bank and created an ongoing discussion with religions around development issues, called World Faith Development Dialogue (Clarke 2009: 385-6).

One example of how environmentalism and spiritual practices are combined is to be found in Eleanor Finnegan's (2011) research on the image of the land among several groups of American Muslims. In Islam the textual tradition concerning land expresses the idea that the land is owned by God and 
given as a gift to God's creatures. Therefore, people can use the land for their own benefit as long as it does not harm others. Specifically for various communities of immigrants and convert Sunni Muslims, as well as for the Nation of Islam, farms play an important role in the religious community. For these Muslims, Islamic ideas and practices as well as the experience of farming, have influenced ideas about land. Among these groups, land has often been a place where Muslims can embody their religious and environmental values and are free to create religious communities, institutions, and identities. It has also helped shape environmental and religious ideas and practices (Finnegan 2011: 71).

\section{Post-secular aspects}

The 1990s saw an explosion of organisations, institutions and publications expressing religious environmental activism. One explanation for this is what is called the globalizing process (Berglund 1999: 196; Hoofd 2009: 200). Globalization combined with the discourse of holism, which sees the planet as a single entity, resonates Beyer that opens up possibilities for religious resonance, connections and movements. As he writes, the environmental issues 'concretize the problematic effects of the global societal system more clearly than others' (Beyer 1994: 208). Concerning environmental holism, among other themes, Rosi Braidotti emphasizes the importance of the eco-philosophical dimension in the post-secular turn (Braidotti 2008: 16). Environmental questions and problems related to them bring people together and initiate numerous social movements, some of them religiously-based, which are often outside or beyond current institutional borders. These specific movements, Beyer argues, represent the potential for new religions (Beyer 1994: 97).

The slogan 'think globally, act locally' reflects in environmental discourse the ways in which universal and particular environmental awareness are simultaneously intertwined. Roland Robertson (1995) uses the term 'glocalization' to describe this mutual interconnection between local and global. The local is often constructed on a trans or super-local basis and one of Robertson's main points is that the notion of separate global homogenization and heterogenization should be left behind. In the current situation it is not a question anymore of either/or, but 'rather of the ways in which both of these two tendencies have become features of life across much of the latetwentieth-century world' (Robertson 1995: 26-7). Environmentalism is an example of the contemporaneous presence of these seemingly opposite poles. 
Environmentalism both promotes the growing awareness of global 'complex connectivity' and advocates a return to being connected to 'place' (Kearns 2007: 306).

These seemingly opposite poles do not seem to be a problem in postsecular spirituality. Popp-Baier's theory of self-controlled religiosity can well be incorporated into the post-secular theme. The main components of selfcontrolled religiosity such as critique (of institutionalised religion), consumption (speed elitism) and the religious/spiritual dimension are all included and combined. The elements which Popp-Baier recognised as being used to construct religion or spirituality are all of a piece with contemporary environmentalism, in that they are to be used for self-enchantment and to improve subjective wellbeing. Worldviews are, as stated earlier no longer necessarily either religious or secular, but may also combine elements of rational secularity with enchanted spirituality. The blurring of the boundaries between secular and religious views and motives occur, as well as the separation of mind and body, rationality and belief, and human and nature.

\section{References}

\section{Baker, Susan \& Robin Morrison}

2011 'Environmental spirituality: grounding our response to climate change.' In: Sigurd Bergmann \& Heather Eaton (eds), Ecological Awareness: Exploring Religion, Ethics and Aesthetics. 59-75. Münster: LIT.

Bauman, Whitney A., Richard R. Bohannon II \& Kevin J. O’Brien

2011 'Introduction'. In: Whitney A. Bauman, Richard R. Bohannon II \& Kevin J. O'Brien (eds), Grounding Religion: A Field Guide to the Study of Religion and Ecology. 1-9. London: Routledge.

\section{Berglund, Jenny}

1999 'Gröna svar på gröna frågor. Muslimskt miljöengagemang.' Svensk Religionshistorisk årsskrift: 196-216.

\section{Beyer, Peter}

1994 Religion and Globalization. London: Sage.

\section{Braidotti, Rosi}

2008 'In spite of the times: the postsecular turn in feminism'. Theory, Culture, Society 25 (1): 1-24.

\section{Clarke, Gerard}

2009 'Religion and international development'. In: Jeffrey Haynes (ed), Routledge Handbook of Religion and Politics. 385-402. London: Routledge.

\section{Finnegan, Eleanor}

2011 'Case study: images of "land" among Muslim farmers in the US'. In: Whitney A. Bauman, Richard R. Bohannon II \& Kevin J. O’Brien (eds), Grounding 
Religion: A Field Guide to the Study of Religion and Ecology. 73-7. London: Routledge.

\section{Geels, Antoon}

2009 'Glocal spirituality for a brave new world'. In: Tore Ahlbäck (ed.), Postmodern Spirituality. 8-24. Åbo: The Donner Institute.

Grim, John \& Mary Evelyn Tucker

2011 'Intellectual and organizational foundations of religion and ecology'. In: Whitney A. Bauman, Richard R. Bohannon II \& Kevin J. O’Brien (eds), Grounding Religion: A Field Guide to the Study of Religion and Ecology. 8195. London: Routledge.

\section{Hoofd, Ingrid $M$.}

2009 'Activism, acceleration, and the humanist aporia: Indymedia intensified in the Age of Neoliberalism'. Cultural Politics 5 (2): 199-228.

\section{Jespers, Frans}

2011 'The scientific study of religious and secular spiritualities'. Journal of Religion in Europe 4: 328-54.

\section{Kearns, Laurel}

2007 'Religion and ecology in the context of globalization'. In: Peter Beyer \& Lori Beaman (eds), Religion, Globalization, and Culture. 305-34. Leiden: Brill.

Koensler, Alexander \& Cristina Papa

2011 'Political tourism in the Israeli-Palestinian space'. Anthropology Today 27 (2): 13-17.

\section{Motak, Dominika}

2009 'Postmodern spirituality and the culture of individualism'. In: Tore Ahlbäck (ed.), Postmodern Spirituality. 149-61. Åbo: The Donner Institute.

\section{Popp-Baier, Ulrike}

2010 'From religion to spirituality-megatrend in contemporary society or methodological artefact? A contribution to the secularization debate from psychology of religion'. Journal of Religion in Europe 3: 34-67.

\section{Robertson, Roland}

1995 'Glocalization: time-space and homogeneity-heterogeneity'. In: Mike Featherstone, Scott Lash \& Roland Roberston (eds), Global Modernities. 25-44. London: Sage.

\section{Thompson, Michael}

1997 Security and Solidarity: An Anti-Reductionist Framework for Thinking about the Relationship between Us and the Rest of Nature. Bergen: LOS-senteret.

Vincett, Giselle \& Linda Woodhead

2009 'Spirituality'. In: Linda Woodhead, Hiroko Kawanami \& Christopher Partridge (eds), Religions in the Modern World: Traditions and Transformations. 319-37. London: Routledge.

\section{Watling, Tony}

2009 Ecological Imaginations in the World Religions: An Ethnographic Analysis. London: Continuum. 